\title{
Motivation to Quit as a Predictor of Smoking Cessation and Abstinence Maintenance among Treated Spanish Smokers
}

Bárbara Piñeiro ${ }^{\mathrm{a}, b^{*}}$, Ana López-Durán ${ }^{\mathrm{a}}$, Elena Fernández del Río ${ }^{\mathrm{a}, \mathrm{c}}$, Úrsula Martínez ${ }^{\mathrm{a}}$, Thomas H. Brandon ${ }^{\mathrm{b}}$, Elisardo Becoña ${ }^{\mathrm{a}}$

${ }^{\text {a}}$ Smoking Cessation and Addictive Disorders Unit, Department of Clinical Psychology and Psychobiology, Faculty of Psychology, University of Santiago de Compostela, Galicia, Spain

${ }^{\mathrm{b}}$ Tobacco Research and Intervention Program, Department of Health Outcomes and Behavior, H. Lee Moffitt Cancer Center, Tampa, FL, USA

${ }^{c}$ Department of Psychology and Sociology, University of Zaragoza, Zaragoza, Spain

*Corresponding Author: Bárbara Piñeiro, PhD., Tobacco Research \& Intervention Program, H. Lee Moffitt Cancer Center, 4115 E. Fowler Avenue, Tampa, FL 33617, USA. Telephone: 813745-1754. E-mail: barbara.pineiro@moffitt.org 


\begin{abstract}
Introduction: Although quitting motivation predicts smoking cessation, there have been inconsistent findings regarding motivation predicting long-term maintenance of abstinence. Moreover, most such research has been conducted in North America and the United Kingdom. The aim of this study was to examine motivation to quit as a predictor of smoking cessation and of abstinence maintenance in a Spanish sample.

Method: The sample comprised 286 Spanish smokers undergoing psychological treatment for smoking cessation. Motivation to quit was assessed pre-treatment and posttreatment with the Readiness to Quit Ladder. Abstinence post-treatment and at 6 month followup was biochemically verified.

Results: Participants with higher levels of pre-treatment and post-treatment motivation were more likely to be abstinent at the end of the treatment $(\mathrm{OR}=1.36)$ and at 6 months followup $(\mathrm{OR}=4.88)$. Among abstainers at the end of the treatment $(61.9 \%)$, higher levels of motivation to quit post-treatment predicted maintaining abstinence at 6 months $(\mathrm{OR}=2.83)$. Furthermore, participants who failed to quit smoking reported higher levels of motivation to quit post-treatment than they had pretreatment $(p<.001)$.

Conclusions: Motivation to quit smoking predicted short and long-term cessation, and also predicted long-term maintenance of abstinence. These results have implications for understanding motivational processes of smoking cessation in general, while extending research to Spanish smokers. They may also help in the design of cessation and relapse-prevention interventions. Specifically, the results suggest that motivational enhancement is important throughout the cessation and maintenance periods.
\end{abstract}

Keywords: motivation to quit, smoking cessation, maintenance abstinence, Spain. 


\section{Introduction}

Most current smokers are interested in smoking cessation and often make multiple quit attempts (CDC, 2011). Many quit attempts are unplanned and do not utilize evidence-based treatments, and it is significantly more difficult for smokers to achieve long-term abstinence from a given cessation attempt without such treatments (Hughes, Keely, \& Naud, 2004). Successful smoking cessation is more likely if smokers utilize evidence-based smoking cessation treatments (Fiore et al., 2008); however, even with evidence-based treatment (consisting of behavioral counseling and/or medication), only around $10 \%$ to $30 \%$ achieve long-term abstinence; a great majority eventually relapse (Fiore et al., 2008). Therefore, identifying modifiable factors that predict long-term smoking cessation is highly relevant.

One such factor that might be associated with short and long-term abstinence is motivation to quit smoking. Commonly, motivation is conceptualized as readiness to change (Biener \& Abrams, 1991) and plays an important role in the smoking cessation process (e.g., Baker, Brandon, \& Chassin, 2004). In fact, accumulating evidence indicates that motivation to quit is a key factor in determining cessation success (e.g., Biener \& Abrams, 1991; Jardin \& Carpenter, 2012). In relapse prevention theory (Marlatt \& Gordon, 1985; Witkiewitz \& Marlatt, 2004), motivation is a critical ingredient to quitting smoking and maintaining abstinence because high levels of motivation are necessary to enact coping behaviors during situations with high risk for relapse. Similarly, in the Transtheoretical Model (Prochaska \& DiClemente, 1983), a theory of health behavior change, motivation to quit is posited to directly increase intention to quit, facilitate cessation attempts, and increase successful abstinence rates.

There has been increasing emphasis on distinguishing between the different phases of the quitting process (motivation, pre-cessation, cessation, and maintenance) when conducting research to develop and test treatments (Baker et al., 2011; Schlam \& Baker, 2012), and it is possible that predictors of quit attempts may differ from predictors of maintenance of abstinence (Borland et al., 2010; West, McEwen, Bolling, \& Owen, 2001; Zhou et al., 2009).

Prior research indicates that motivation to quit is one of example of such a predictor, such that motivation to quit is strongly related to quit attempts but not to cessation maintenance (Borland et al., 2010; West et al., 2001; Zhou et al., 2009). However, other studies have found that higher levels of motivation increase the likelihood of maintaining smoking cessation (Boardman, Catley, Mayo, \& Ahluwalia, 2005; Heppner et al., 2011) and that motivation to quit predicts abstinence at 6 months (Williams, Gagne, Ryan, \& Deci, 2002) suggesting that there are different results and considerations in how important motivation to quit may be to successfully quit smoking. Indeed, Borland et al. (2010) point out that motivation is a complex set of beliefs that is not fully understood, especially as it relates to long-term cessation.

Given the inconsistent findings about the role of motivation in the maintenance of smoking abstinence, it may be useful to explore this construct across populations. Indeed, motivation to quit has been studied primarily in smokers from North America and the United Kingdom. Given that Spain has a higher prevalence of smoking (24\% Spanish Ministry of Health, 2013), more studies are necessary in this population to improve knowledge of the culture-specific mechanisms of change, and to identify modifiable factors that predict long-term smoking cessation. As noted by Carballo et al. (2014), more studies of the process of change are 
needed to a better inform the development of interventions for Hispanics across different cultures and countries.

Although motivation has been frequently examined as a predictor of cessation and as a predictor of quit attempts, less attention has been paid to motivation as a predictor of maintenance of abstinence. The present study aimed to examine the role of motivation to quit as a predictor of short-term and long-term smoking cessation and as a predictor of abstinence maintenance at 6 months follow-up among a Spanish sample of smokers who received an evidence-based psychological treatment for smoking cessation. Based on the results found in previous studies (Boardman et al., 2005; Heppner et al., 2011; Jardin \& Carpenter, 2012; Williams et al., 2002) we hypothesized that higher levels of motivation to quit would predict smoking cessation at the end of the treatment and at 6 months follow-up, and maintenance of smoking abstinence at 6 months follow-up.

\section{Methods}

\subsection{Participants}

The study sample consisted of Spanish smokers $(\mathrm{N}=286)$ seeking treatment for smoking cessation at the Smoking Cessation and Addictive Disorders Unit at the University of Santiago de Compostela (Spain) during the period of September 2009 to May 2012. Recruitment of participants was carried out by advertisements in the media (radio, press and local television), referrals from past smokers who had previously sought treatment, or referrals from general practitioners. Participants met the following inclusion criteria: at least 18 years of age; desire to participate in the treatment program; smoking $\geq 10$ cigarettes per day (CPD); and having completed the questionnaires in the pretreatment assessment. Exclusion criteria included the following: a diagnosis of a severe mental illness (bipolar disorder and/or psychotic disorder); concurrent dependence on other substances (cocaine, cannabis, and/or heroin); having participated in the same or similar treatment over the previous year; having received another type of effective smoking cessation treatment (nicotine replacement therapy, bupropion, varenicline) in the past year; suffering from a severe physical pathology that would require immediate medical intervention (e.g., recent myocardial infarction, pneumothorax); smoking tobacco other than cigarettes (e.g., cigars); and failing to attend the first treatment session.

\subsection{Measures}

All participants completed the Smoking Habit questionnaire (Becoña, 1994), which obtains information on sociodemographic variables (e.g., gender, age, marital status, educational level) and aspects related to smoking and smoking history (e.g., number of cigarettes smoked per day, number of years smoking, number of quit attempts).

For the assessment of nicotine dependence, we used the Fagerström Test for Nicotine Dependence (FTND; Heatherton, Kozlowski, Frecker, \& Fagerström, 1991; Spanish version by Becoña \& Vázquez, 1998), a six-item scale with scores ranging from 0 to 10, higher scores indicating greater dependence. 
To assess motivation to quit smoking, participants completed the Spanish version of the Readiness to Quit Ladder (Abrams et al., 2003), a continuous measure of motivation and readiness to quit, with options ranging from 1 , not considering quitting smoking at all in the near future ("I enjoy smoking and have decided not to quit smoking for my lifetime. I have no interest in quitting"), to 10, having already quit smoking ("I have quit smoking and I will never smoke again"). Higher scores on the ladder are associated with greater motivation to quit smoking. The range of scores in the current sample was 1-8, given that the sample comprises only current smokers.

We used the Micro+ Smokerlyzer® (Bedfont Scientific Ltd, Sittingbourne, England) to measure carbon monoxide $(\mathrm{CO})$ in expired air, to corroborate self-reported abstinence at the end of the treatment and at 6-month follow-up. Abstinence was confirmed using a CO cut-off $<10$ ppm, as per West, Hajek, Stead, and Stapleton (2005) and SRNT Subcommittee on Biochemical Verification (2002).

\subsection{Procedure}

At the initial assessment, we administered the measurements described above in a single session, and the Readiness to Quit Ladder was administered again at the end of the treatment. All smokers provided informed consent prior to study enrollment, and the Bioethics Committee of the University of Santiago de Compostela approved the study.

The psychological treatment administered comprised the evidence-based Smoking Cessation Program (Programa para Dejar de Fumar) by Becoña (2007), a manualized cognitive-behavioral treatment (CBT) that comprises 6 group-format sessions over six weeks (one session per week). It consists of the following elements: therapeutic contract, self-reports, graphic representation of cigarette-smoking rate, general information on tobacco, nicotine fading, stimulus control, strategies for avoiding nicotine withdrawal syndrome, physiological feedback on cigarette consumption (assessment of $\mathrm{CO}$ in expired air), training in relapse prevention strategies (training in assertiveness, relaxation, problem-solving, changing mistaken beliefs, management of anxiety and anger, physical exercise, weight control and selfreinforcement) and training in the maintenance of abstinence. In this intervention, smokers plan to set a quit date between the $4^{\text {th }}$ and $5^{\text {th }}$ session. The treatment was administered by psychologists trained in its application, and the groups were composed of 6-8 participants, with group assignment based on their schedule availability. Smoking status at the end of the treatment was biochemically verified by testing CO level (24-hour point prevalence abstinence, cut-off point of $<10 \mathrm{ppm}$ to be considered a non-smoker; West et al., 2005).

After the treatment, there was face-to-face follow-up at 6 months. An intent-to-treat model was adopted when it was not possible to locate the participants (Hall et al., 2001). They were considered to be smokers at the same level (in terms of number of cigarettes and nicotine content) as in the pretreatment assessment. Smoking status at 6 months follow-up to assess maintained abstinence was coded into two categories: 1) abstainers (smokers who quit smoking at the end of the treatment and maintained abstinence at 6 months follow-up), and 2) smokers (participants who never quit smoking or who quit smoking at the end of the treatment and reported smoking during the 7 days prior to the date of the 6 months follow-up).

\subsection{Data analysis}


Descriptive statistics were conducted to determine the sample's demographic and smoking history characteristics. Differences between those who were abstinent or not at the end of the treatment were determined using chi-square test for categorical variables and independent samples $t$ tests for continuous variables. Cohen's $d$ effect size are presented when $t$-tests were significant. Cohen's $d$ ranges were labeled as small: $(\leq 0.4)$, medium $(0.5-0.7)$, and large $(\geq 0.8)$ (Cohen, 1988).

The role of motivation to quit as a predictor of abstinence at the end of the treatment and at 6 months follow-up, and as predictor of maintaining smoking abstinence at 6 months followup was assessed using unadjusted multiple logistic regressions (forward stepwise selection).

All analyses were conducted with SPSS version 21.0, with a $p$ value of less than .05 considered significant.

\section{Results}

\subsection{Sample characteristics}

Table 1 shows the baseline characteristics of participants. The sample was made up of 286 smokers $(61.2 \%$ female), with a mean age of 41.58 years $(S D=10.94)$. Half $(51.4 \%)$ of the participants were married or lived with a partner, and approximately half (43\%) had obtained some college or technical school. Participants smoked a mean of 21.33 CPD before the treatment $(S D=8.00$, range 10-40), began smoking regularly at a mean age of 18.05 years $(S D=4.47)$, and had been smoking an average of 23.13 years $(S D=10.59)$. The mean FTND score was 5.32 $(\mathrm{SD}=2.08)$, moderately dependent, and $43 \%$ of the sample had made a quit attempts in the previous 12 months. The mean motivation was $6.74(S D=0.92$, range $=1-10)$, representing plans to quit smoking between 30 days and 6 months. Figure 1 shows the distribution of scores on the Readiness to Quit Ladder before the treatment $(N=286)$.

\subsection{Relationship between motivation to quit pre-treatment and socio-demographic and cigarette consumption variables}

The only baseline variables associated with motivation to quit pre-treatment were age and having made quit attempts in the previous 12 months. Participants who were $>40$ years old scored higher in the Readiness to Quit Ladder $[M=6.86(S D=0.93)$ for $>40$ years, and $M=$ $6.61(S D=0.90)$ for $\leq 40$ years; $\mathrm{t}=-2.29, p<.05, d=0.27]$, as did those who made quit attempts in the previous 12 months $[M=6.89(S D=0.82)$ for yes quit attempts, and $M=6.63(S D=0.98)$ for no quit attempts; $\mathrm{t}=-2.46, p \leq .01, d=0.29$ ).

\subsection{End of the treatment}

At the end of the treatment, 177 (61.9\%) smokers achieved abstinence, and 109 (38.1\%) continued smoking. We did not find significant differences between smoker status and sociodemographic variables. However, regarding smoking related-variables, there were significant differences between smokers and abstainers. Smokers compared to abstainers had smoked more CPD before the treatment $[\mathrm{M}=23.98(S D=9.10)$ smokers, $\mathrm{M}=19.70(S D=6.77)$ abstainers; $t$ $=4.24, p<.001, d=0.53]$, had smoked more years $[\mathrm{M}=24.98(S D=10.53)$ smokers, $\mathrm{M}=$ 
$21.98(S D=10.50)$ abstainers; $t=2.34, p<.05, d=0.29$ ] and presented more nicotine dependence $[\mathrm{M}=5.97(S D=1.99)$ smokers, $\mathrm{M}=4.92(S D=2.04)$ abstainers; $t=4.29, p<.001$, $d=0.52$ (see Table 1$)$.

Moreover, we found that smokers post-treatment reported higher levels of motivation at the end of the treatment than they did at the beginning of treatment $[\mathrm{M}=6.61(S D=0.98)$ pretreatment, $\mathrm{M}=7.33$ (SD = 1.00) post-treatment; $t=-4.98, p<.001, d=0.48$ ].

\subsection{Predictors of abstinence at the end of the treatment and at 6 months follow-up}

To examine predictors of abstinence at the end of the treatment and at 6 months followup, multiple binary logistic regression analyses with forward stepwise selection were performed (see Table 2). Adopting as the criterion variable abstinent at the end of the treatment, and as predictor variables: age, gender, nicotine dependence, number of CPD before treatment, motivation pre-treatment, and whether a quit attempt was made in the previous 12 months. We found that age, nicotine dependence, and pre-treatment motivation were associated with abstinence at the end of the treatment. That is, having 40 or less years $(\mathrm{OR}=2.01)$, having low nicotine dependence (FTND < 6) $(\mathrm{OR}=2.45)$, and higher pre-treatment motivation $(\mathrm{OR}=1.36)$ increased the likelihood of being abstinent at the end of the treatment.

Using the same stepwise approach to predict abstinence at the 6-month follow-up, with post-treatment motivation as an additional predictor, we found that fewer CPD before treatment $(\mathrm{OR}=2.03)$, and higher motivation to quit post-treatment $(\mathrm{OR}=4.88)$ were associated with greater likelihood of being abstinent at 6 months (see Table 2).

\subsection{Predictors of maintenance of abstinence}

To examine predictors of maintenance of abstinence analyses were limited to the 177 participants who quit smoking by the end of treatment (continuous abstinence rate for the 6 months follow-up was $49.2 \%, \mathrm{n}=87$ ). A binary logistic regression analysis was performed (see Table 2). Adopting as the criterion variable abstinence, and as predictor variables, age, gender, nicotine dependence, CPD before treatment, motivation pre-treatment, motivation posttreatment, and made quit attempt in the previous 12 months. We found that higher motivation post-treatment increased the likelihood of being abstinent at 6 months follow-up $(\mathrm{OR}=2.83)$.

\section{Discussion}

The aim of the present study was to examine the role of motivation to quit as predictor of smoking cessation and cessation maintenance among Spanish smokers who received psychological treatment for smoking cessation. Overall, the results indicate that motivation plays an important role in predicting smoking cessation at the end of the treatment, and in predicting maintenance at 6 months follow-up. Higher levels of motivation to quit pre-treatment predicted cessation at the end of the treatment, but not abstinence maintenance at 6 months follow-up. However, motivation to quit post-treatment predicted long-term abstinence and abstinence maintenance at 6 months follow-up. 
Consistent with our hypothesis, higher levels of motivation to quit predicted smoking cessation and maintenance of abstinence. These results are consistent with previous studies (Biener \& Abrams, 1991; Jardin \& Carpenter, 2012) where initial levels of motivation to quit predicted success with smoking cessation, and they are consistent with the results found by Heppner et al. (2011) where motivation predicted continuous smoking abstinence in a sample of pregnant women. In addition, our results are consistent with previous research that found motivation to be a predictor of abstinence at 3 and 6 months (Wee, West, Bulgiba, \& Shahab, 2011; Williams et al., 2002). However, our results are contrary to those that found that motivation was unrelated to cessation maintenance (Borland et al., 2010; West et al., 2001; Zhou et al., 2009). Perhaps this discrepancy could be because those studies examined associations between motivation to quit in population samples in the absence of interventions, whereas the present study used a clinical sample in which participants received a psychological intervention to quit smoking. In fact, as the frequency distribution of smoker's scores show on the Readiness to Quit Ladder, the majority of the sample consisted of smokers motivated to quit.

The results also show that motivation to quit was associated with quit attempts and age. These findings are consistent with previous studies (Borland et al., 2010; Jardin \& Carpenter, 2012; West et al., 2001; Zhou et al., 2009). However, the fact that motivation was related to both making a quit attempt and success quitting smoking deviates from previous literature (Borland et al., 2010; West et al., 2001; Zhou et al., 2009). In addition, consistent with previous findings (Ferguson et al., 2003; Vangeli et al., 2011), our results reveled that lower nicotine dependence levels predicted abstinence. This is similar to results with other substances for which baseline urine toxicology has predicted treatment outcomes (e.g., Stitzer et al., 2007). Furthermore, in the current study, we found that age was a predictor of abstinence at the end of the treatment, such that younger participants were more likely to be abstinent at the end of treatment. However, regarding age, the literature varies in the degree of consistency (Velicer, Redding, Sun, \& Prochaska, 2007).

Our results show that smokers who failed to quit at the end of the treatment reported higher levels of motivation at that time than they had at pre-treatment. This result is consistent with other studies (e.g., Boardman, et al., 2005; Hughes et al., 2014; Joseph, Rice, An, Mohiuddin, \& Lando, 2004), in which smokers who fail to quit are often not discouraged but are ready to try again in the near future. In fact, Joseph et al. (2004) found that those who try to stop and fail are more motivated to try again compared with smokers who have not tried to quit. Therefore, these findings suggest that interventions that continue to engage smokers after a failed quit attempt may be helpful. For example, Motivational Interviewing (Miller \& Rollnick, 1991), a patient-centered counseling technique that enhances an individual's intrinsic motivation for change, may be valuable immediately after a failed quit attempt. Additionally, there is evidence that abstinence can be maintained via extended or sustained counseling or self-help interventions (Brandon et al., 2004; Hall, Humfleet, Reus, Munoz, \& Cullen, 2004). That is, extended contact may extend motivation.

The results also showed that smokers who identified delayed motivation to quit were less likely achieves cessation. For example, $25.5 \%$ of the smokers who attended the Smoking Cessation Program reported that they were motivated to quit smoking in the next 6 months, rather than sooner. However, only a small percentage $(7.34 \%$ ) of those smokers achieved abstinence by the 6-month follow-up. Additionally, although $61.9 \%$ of smokers achieved 
abstinence at the end of the treatment, 31.5\% had relapsed by the 6-month follow-up. These results are consistent with previous literature showing relapse to be the most common outcome of the smoking cessation process (Fiore et al., 2008; Hughes et al., 2004), and they are in line with previous studies in Spanish smokers (Piñeiro \& Becoña, 2013). More effective relapseprevention interventions are necessary for avoiding relapse. In fact, multiple literature reviews have documented the need for such interventions (e.g., Agboola et al., 2010; Brandon et al., 2007). The results suggest that smokers may benefit from interventions that persist over time for extending motivation levels for quitting smoking and maintaining abstinence, such as the extended self-help booklets used by Brandon and his colleagues (2000, 2004).

Motivation has been understudied during maintenance, compared to constructs such as craving and withdrawal syndrome. Indeed, these finding suggest that it may be fruitful to examine dynamic processes in post-cessation motivation as Simmons, Heckman, Ditre, and Brandon (2010) have suggested. These authors developed a more dynamic instrument, the Abstinence-Related Motivational Engagement (ARME) scale, to provide a more complete picture of the link between fluctuating motivation levels and continued smoking abstinence.

These results should be interpreted with attention to their limitations. First, the sample consisted of smokers who were actively seeking to quit. Although this treatment sample extends and compliments much of the previous research on self-quitters, Hughes et al. (1997) and Le Strat et al. (2011) note that the results with such smokers may not generalize to smokers in the general population. Second, we excluded smokers who smoked fewer than $10 \mathrm{CPD}$, which may have also restricted the range of cessation motivation. Third, quitting motivation was, as usual, measured by self-report, which presents the possibility of bias and demand effects. Finally, although self-reported abstinence was confirmed with expired $\mathrm{CO}$, it is possible that some participants might have abstained only on the day of testing.

Despite these limitations, our findings support the importance of motivation in the smoking cessation process and in the maintenance of abstinence, as posited in prominent theories of addictive behaviors (e.g., relapse prevention theory; Marlatt \& Gordon, 1985; Witkiewitz \& Marlatt, 2004). Our findings demonstrate the predictive utility of motivation for successful smoking and for maintenance of smoking abstinence. These results further clarify the role of motivational processes in smoking cessation and maintenance of abstinence, and they extend this literature to Spanish smokers. Moreover, they support the use of motivational enhancement interventions, not only to induce initial cessation, but to enhance maintenance and aid recovery from relapse. 


\section{References}

Abrams, D. B., Niaura, R., Brown, R. A., Emmons, K. M., Goldstein, M. G., \& Monti, P. M. (2003). The tobacco treatment handbook: A guide to best practices. New York: Guildford Press.

Agboola, S., McNeill, A., Coleman, T., \& Leonardi Bee, J. (2010). A systematic review of the effectiveness of smoking relapse prevention interventions for abstinent smokers. Addiction, 105, 1362-1380. doi: 10.1111/j.1360-0443.2010.02996.x.

Baker, T. B., Brandon, T. H., \& Chassin, L. (2004). Motivational influences on cigarette smoking. Annual Review of Psychology, 55, 463-491. doi: 10.1146/annurev.psych.55.090902.142054

Baker, T. B., Mermelstein, R., Collins, L. M., Piper, M. E., Jorenby, D. E., Smith, S. S., ... Fiore, M. C. (2011). New methods for tobacco dependence treatment research. Annals of Behavioral Medicine, 41, 192-207. doi: 10.1007/s12160-010-9252-y

Becoña, E. (1994). Evaluación de la conducta de fumar [Assessment of smoking behaviour]. In J. L. Graña (Ed.), Conductas Adictivas: Teoría, evaluación y tratamiento (pp. 403-454). Madrid: Debate.

Becoña, E. (2007). Programa para Dejar de Fumar [Smoking Cessation Programme]. Vigo, Spain: Nova Galicia Edicións.

Becoña, E., \& Vázquez, F. L. (1998). The Fagerström Test for Nicotine Dependence in a Spanish sample. Psychological Reports, 83, 1455-1458. doi:10.2466/pr0.1998.83.3f.1455

Biener, L., \& Abrams, D. B. (1991). The Contemplation Ladder: Validation of a measure of readiness to consider smoking cessation. Health Psychology, 10(5), 360-365. doi:10.1037/0278-6133.10.5.360

Boardman, T., Catley, D., Mayo, M. S., \& Ahluwalia, J. S. (2005). Self-efficacy and motivation to quit during participation in a smoking cessation program. International Journal of Behavioral Medicine, 12(4), 266-272.doi:10.1207/s15327558ijbm1204_7

Borland, R., Yong, H. H., Balmford, J., Cooper, J., Cummings, K. M., O'Connor, R. J., ... Fong, G. T. (2010). Motivational factors predict quit attempts but not maintenance of smoking cessation: Findings from the International Tobacco Control Four country project. Nicotine \& Tobacco Research, 12 Suppl, S4-11. doi:10.1093/ntr/ntq050

Brandon, T. H., Collins, B. N., Juliano, L. M., \& Lazev, A. B. (2000). Preventing relapse among former smokers: A comparison of minimal interventions through telephone and mail. Journal of Consulting and Clinical Psychology, 68, 103-113. doi:10.1037/0022006X.68.1.103

Brandon, T. H., Meade, C. D., Herzog, T. A., Chirikos, T. N., Webb, M. S., Cantor, A. B. (2004). Efficacy and cost-effectiveness of a minimal intervention to prevent smoking relapse: Dismantling the effects of amount of content versus contact. Journal of Consulting and Clinical Psychology, 72, 797-808. doi: 10.1037/0022-006X.72.5.797 
Brandon, T. H., Vidrine, J. I., \& Litvin, E. B. (2007). Relapse and relapse prevention. Annual Review of Clinical Psychology, 3, 257-284. doi:

10.1146/annurev.clinpsy.3.022806.091455

Carballo, J. L., Sobell, L. C., Dum, M., Sobell, M. B., Fernández-Hermida, J. R., Secades-Villa, R., \& García-Rodríguez, O. (2014). Self-change among Spanish speakers with alcohol and drug use disorders in Spain and the United States. Addictive Behaviors, 39, 225-230. doi:10.1016/j.addbeh.2013.10.013

Centers for Disease Control and Prevention. (2011). Cigarette smoking-United States, 19652008. Morbidity \& Mortality Weekly Report, Surveillance Summaries 60, 109-113. Retrieved from http://www.cdc.gov/mmwr/preview/mmwrhtml/su6001a24.htm

Cohen, J. (1988). Statistical power analysis for the behavioral sciences. Hillsdale, NJ: Erlbaum. Ferguson, J. A., Patten, C. A., Schroeder, D. R., Offord, K. P., Eberman, K. M., \& Hurt, R. D. (2003). Predictors of 6-month tobacco abstinence among 1224 cigarette smokers treated for nicotine dependence. Addictive Behaviors, 28, 1203-1218. doi:10.1016/S03064603(02)00260-5

Fiore, M. C., Jaén, C. R., Baker, T. B., Bailey, W. C., Benowitz, N. L., Curry, S. J., ... Wewers, M E. (2008). Treating tobacco use and dependence: 2008 update. Clinical practice guideline. Rockville, MD: U. S. Department of Health and Human Services, Public Health Service.

Hall, S. M., Delucchi, K. L., Velicer, W. F., Kahler, C. W., Ranger-Moore, J., Hedeker, D., . . . Niaura, R. (2001). Statistical analysis of randomized trials in tobacco treatment: Longitudinal designs with dichotomous outcome. Nicotine \& Tobacco Research, 3(3), 193-202. doi: 10.1080/14622200110050411

Hall, S. M., Humfleet, G. L., Reus, V. I., Muñoz, R. F., \& Cullen, J. (2004). Extended nortriptyline and psychological treatment for cigarette smoking. The American Journal of Psychiatry, 161, 2100-2107. doi:10.1176/appi.ajp.161.11.2100

Heatherton, T. F., Kozlowski, L. T., Frecker, R. C., \& Fagerstrom, K. O. (1991). The Fagerström Test for Nicotine Dependence: A revision of the Fagerström Tolerance Questionnaire. British Journal of Addiction, 86(9), 1119-1127. doi:10.1111/j.1360-0443.1991.tb01879.x

Heppner, W. L., Ji, L., Reitzel, L. R., Castro, Y., Correa-Fernandez, V., Vidrine, J. I., . . Wetter, D. (2011). The role of prepartum motivation in the maintenance of postpartum smoking abstinence. Health Psychology, 30(6), 736-745. doi:10.1037/a0025132

Hughes, J. R., Giovino, G. A., Klevens, R. M., \& Fiore, M. C. (1997). Assessing the generalizability of smoking studies. Addiction, 92(4), 469-472. doi:10.1111/j.13600443.1997.tb03378.x

Hughes, J. R., Keely, J., \& Naud, S. (2004). Shape of the relapse curve and long-term abstinence among untreated smokers. Addiction, 99, 29-38. doi:10.1111/j.1360-0443.2004.00540.x 
Hughes, J. R., Solomon, L. J., Naud, S., Fingar, J. R., Helzer, J. E., \& Callas, P. W. (2014). Natural history of attempts to stop smoking. Nicotine \& Tobacco Research, 16(9), 11901198. doi:10.1093/ntr/ntu052

Jardin, B. F., \& Carpenter, M. J. (2012). Predictors of quit attempts and abstinence among smokers not currently interested in quitting. Nicotine \& Tobacco Research, 14(10), $1197-$ 1204. doi: $10.1093 /$ ntr/nts015

Joseph, A. M., Rice, K., An, L. C., Mohiuddin, A., \& Lando, H. (2004). Recent quitters' interest in recycling and harm reduction. Nicotine \& Tobacco Research, 6(6), 1075-1077. doi:10.1080/14622200412331324893

Le Strat, Y., Rehm, J., \& Le Foll, B. (2011). How generalisable to community samples are clinical trial results for treatment of nicotine dependence: A comparison of common eligibility criteria with respondents of a large representative general population survey. Tobacco Control, 20(5), 338-343. doi:10.1136/tc.2010.038703

Marlatt, G. A., \& Gordon, J. R. (Eds.). (1985). Relapse prevention: Maintenance strategies in the treatment of addictive behaviors. New York: Guilford Press.

Miller, W.R. \& Rollnick, S. (1991). Motivational Interviewing: Preparing People to Change Addictive Behaviour. New York: Guilford.

Piñeiro, B., \& Becoña, E. (2013). Relapse situations according to Marlatt's taxonomy in smokers. Spanish Journal of Psychology, 16, E91. doi: 10.1017/sjp.2013.91.

Prochaska, J. O., \& DiClemente, C. C. (1983). Stages and processes of self-change of smoking: toward an integrative model of change. Journal of Consulting and Clinical Psychology, 51, 390-395. doi:10.1037/0022-006X.51.3.390

Schlam, T. R. y Baker, T. B. (2012). Interventions for tobacco smoking. The Annual Review of Clinical Psychology, 9, 1-28. doi:10.1146/annurev-clinpsy-050212-185602

Simmons, V. N., Heckman, B. W., Ditre, J. W., \& Brandon, T. H. (2010). A measure of smoking abstinence-related motivational engagement: Development and initial validation. Nicotine \& Tobacco Research, 12(4), 432-437. doi:10.1093/ntr/ntq020

Spanish Ministry of Health (2013). Encuesta Nacional de Salud: ENSE 2011-2012. [National Health Survey: ENSE 2011-2012]. http://www.msc.es/estadEstudios/estadisticas/encuestaNacional/encuesta2011.htm

SRNT Committee on Biochemical Verification (2002). Biochemical verification of tobacco use and cessation. Nicotine \& Tobacco Research, 4, 149-159. doi:10.1080/14622200210123581

Stitzer, M. L., Petry, N., Peirce, J., Kirby, K., Killeen, T., Roll, J., ... Brown, C. (2007). Effectiveness of abstinence-based incentives: Interaction with intake stimulant test results. Journal of Consulting and Clinical Psychology, 75, 805-811. doi:10.1037/0022006X.75.5.805 
Vangeli, E., Stapleton, J., Smit, E. S., Borland, R., \& West, R. (2011). Predictors of attempts to stop smoking and their success in adult general population samples: A systematic review. Addiction, 106(12), 2110-2121. doi:10.1111/j.1360-0443.2011.03565.x

Velicer, W. F., Redding, C. A., Sun, X., \& Prochaska, J. O. (2007). Demographic variables, smoking variables, and outcome across five studies. Health Psychology, 26(3), 278-287. doi:10.1037/0278-6133.26.3.278

Wee, L. H., West, R., Bulgiba, A., \& Shahab, L. (2011). Predictors of 3-month abstinence in smokers attending stop-smoking clinics in Malaysia. Nicotine \& Tobacco Research, 13, 151-156. doi: 10.1093/ntr/ntq221

West, R., Hajek, P., Stead, L., \& Stapleton, J. (2005). Outcome criteria in smoking cessation trials: Proposal for a common standard. Addiction, 100, 299-303. doi:10.1111/j.13600443.2004.00995.x

West, R., McEwen, A., Bolling, K., \& Owen, L. (2001). Smoking cessation and smoking patterns in the general population: A 1-year follow-up. Addiction, 96(6), 891-902. doi: $10.1080 / 09652140020051013$

Williams, G. C., Gagne, M., Ryan, R. M., \& Deci, E. L. (2002). Facilitating autonomous motivation for smoking cessation. Health Psychology, 21(1), 40-50. doi:10.1037/02786133.21.1.40

Witkiewitz, K., \& Marlatt, G. A. (2004). Relapse prevention for alcohol and drug problems: That was Zen, this is Tao. American Psychologist, 59, 224-235._doi:10.1037/0003066X.59.4.224

Zhou, X., Nonnemaker, J., Sherrill, B., Gilsenan, A., Coste, F., \& West, R. (2009). Attempts to quit smoking and relapse: Factors associated with success or failure from the ATTEMPT cohort study. Addictive Behaviors, 34, 365-373. doi:10.1016/j.addbeh.2008.11.013 
Table 1. Baseline characteristics participants and their association with smoking status at the end of the treatment $(N=286)$.

\begin{tabular}{|c|c|c|c|c|c|}
\hline & \multicolumn{4}{|c|}{ End of the treatment } & \multirow[b]{2}{*}{ Cohen $d$} \\
\hline & $\begin{array}{c}\text { Total sample } \\
(\mathrm{N}=286) 100 \%\end{array}$ & $\begin{array}{c}\text { Abstainers } \\
\mathrm{n}=177(61.9 \%)\end{array}$ & $\begin{array}{c}\text { Smokers } \\
\mathrm{n}=109(38.1 \%)\end{array}$ & $\chi^{2} / t$ & \\
\hline \multicolumn{6}{|l|}{ Demographics variables } \\
\hline Age (years), Mean (SD) & $41.58(10.94)$ & 40.88 (11.17) & $42.71(10.51)$ & 1.37 & \\
\hline Gender $(\mathrm{n}, \%)$ & & & & 0.85 & \\
\hline Male & $111(38.8)$ & $65(36.7)$ & $46(42.2)$ & & \\
\hline Female & $175(61.2)$ & $112(63.3)$ & $63(57.8)$ & & \\
\hline Marital status (n, \%) & & & & 1.01 & \\
\hline Single & $100(35.0)$ & $65(36.7)$ & $35(32.1)$ & & \\
\hline Married/ living with a partner & $147(51.4)$ & $89(50.3)$ & $58(53.2)$ & & \\
\hline Divorced/separated & $31(10.8)$ & $19(10.7)$ & $12(11.0)$ & & \\
\hline Widowed & $8(2.8)$ & $4(2.3)$ & $4(1.4)$ & & \\
\hline Educational level (n, \%) & & & & 3.66 & \\
\hline$<$ HS diploma & $65(22.7)$ & $43(24.3)$ & $22(20.2)$ & & \\
\hline HS diploma or GED & $96(33.6)$ & $52(29.4)$ & $44(40.4)$ & & \\
\hline College or technical school & $125(43.7)$ & $82(46.3)$ & $43(39.4)$ & & \\
\hline \multicolumn{6}{|l|}{ Smoking variables } \\
\hline Number of cigarettes per day, Mean (SD) & $21.3(8.00)$ & $19.70(6.77)$ & $23.98(9.10)$ & $4.24 * * *$ & 0.53 \\
\hline Years of daily smoking, Mean (SD) & $23.13(10.59)$ & $21.98(10.50)$ & $24.98(10.53)$ & $2.34 *$ & 0.29 \\
\hline Age became a daily smoker, Mean (SD) & $18.05(4.47)$ & $17.91(3.58)$ & $18.28(5.64)$ & 0.61 & \\
\hline Made quit attempts in last 12 months, (yes), (n, \%) & $123(43.0)$ & $76(42.9)$ & $47(43.1)$ & 0.01 & \\
\hline Nicotine Dependence (FTND), Mean (SD) & $5.32(2.08)$ & $4.92(2.04)$ & $5.97(1.99)$ & $4.29 * * *$ & 0.52 \\
\hline Motivation to quit, Mean (SD) & $6.74(0.92)$ & $6.82(0.88)$ & $6.61(0.98)$ & -1.88 & \\
\hline
\end{tabular}

Note . HS = High school; GED = general education diploma; FTND = Fagerström Test For Nicotine Dependence.

$* p<.05 ; * * p<.01 ; * * * p<.001$. 
Figure 1. Frequency distribution of smoker's scores on the Readiness to Quit before the treatment.

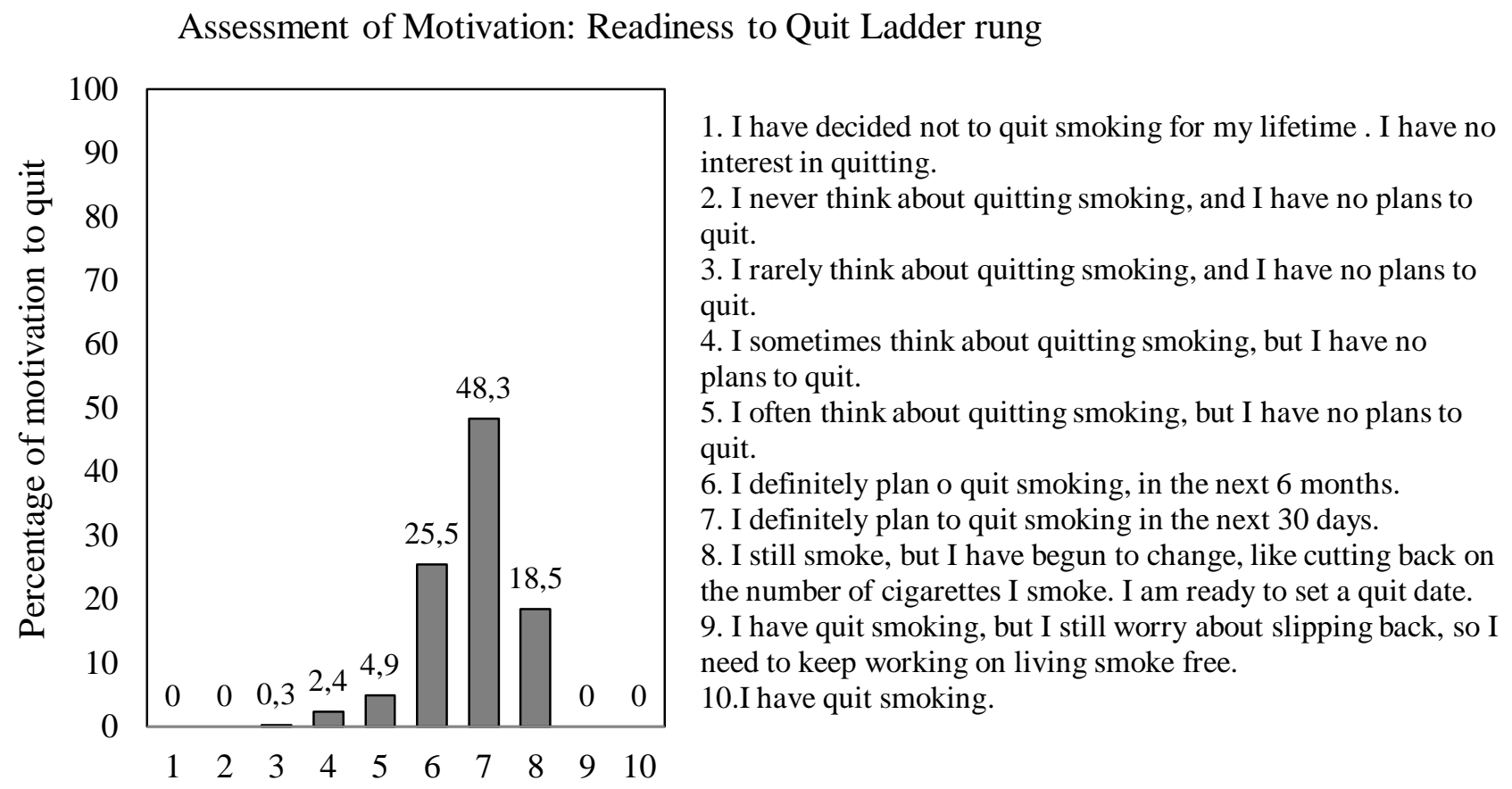


Table 2. Logistic regression analysis output as predictors of abstinence at the end of the treatment and at 6 months follow up $(\mathrm{N}=286)$, and predictors of the maintenance abstinence at 6 months follow up $(\mathrm{n}=177)$.

\begin{tabular}{|c|c|c|c|c|c|}
\hline & $\mathrm{B}^{\mathrm{a}}$ & Wald & $p$ value & $O R$ & OR $(95 \% \mathrm{CI})$ \\
\hline \multicolumn{6}{|l|}{ End of the treatment } \\
\hline Age $(\leq 40)$ & 0.70 & 7.06 & 0.008 & 2.01 & $1.20-3.36$ \\
\hline Motivation to quit-pre & 0.31 & 4.83 & 0.028 & 1.36 & $1.03-1.80$ \\
\hline Nicotine Dependence, FTND $(<6)$ & 0.90 & 12.37 & 0.001 & 2.45 & $1.49-4.03$ \\
\hline Constant & -2.35 & 5.66 & 0.017 & 0.10 & \\
\hline \multicolumn{6}{|l|}{6 months follow-up } \\
\hline Number of CPD $(<20)$ & 0.708 & 3.97 & 0.046 & 2.03 & $1.01-4.07$ \\
\hline Motivation post-treatment & 1.584 & 40.55 & 0.001 & 4.88 & $2.99-7.94$ \\
\hline Constant & -15.11 & 43.35 & 0.001 & 0.00 & \\
\hline \multicolumn{6}{|c|}{ Maintenance abstinence 6 months follow-up } \\
\hline Motivation Post-treatment & 1.04 & 10.30 & 0.001 & 2.83 & $1.50-5.35$ \\
\hline Constant & -9.67 & 10.18 & 0.001 & 0.01 & \\
\hline
\end{tabular}

